\title{
BONE MARROW EXAMINATION- A TWO-YEAR STUDY AT A TERTIARY CARE CENTRE
}

\author{
Zaheda Kauser¹, Naga Kalyani Pathuri², Anunayi Jeshtadi³, Ezhil Arasi Nagamuthu \\ ${ }_{1}^{1}$ Assistant Professor, Department of Pathology, Osmania Medical College, Hyderabad, Telangana. \\ ${ }^{2}$ Assistant Professor, Department of Pathology, Osmania Medical College, Hyderabad, Telangana. \\ ${ }_{3}^{3}$ Associate Professor, Department of Pathology, Osmania Medical College, Hyderabad, Telangana. \\ ${ }^{4}$ Professor and HOD, Department of Pathology, Osmania Medical College, Hyderabad, Telangana.
}

\begin{tabular}{l} 
ABSTRACT \\
\hline BACKGROUND \\
The incidence of haematological diseases is quite alarming in Indian population. The commonest presenting symptom in most of \\
these conditions is anaemia. Apart from peripheral blood examination bone marrow analysis plays a crucial role in diagnosis, \\
confirmation of the diagnosis and in follow-up of treatment. Many a times bone marrow examination forms the key to diagnose a \\
non-haematological condition also. \\
Aims and Objectives- The present study was carried out to identify the frequency of various causes leading to bone marrow \\
evaluation of a patient in our setup. The data was analysed and the bone marrow aspiration findings were interpreted.
\end{tabular}

\section{MATERIALS AND METHODS}

This is a retrospective descriptive study carried out at the Upgraded Department of Pathology, Osmania General Hospital, a tertiary care centre for a period of two years from July 2015 to June 2017. Bone marrow aspiration along with biopsies wherever required for suspected haematological disorders were carried out on 220 cases during the study period. Leishman stained slides were retrieved and examined.

\section{RESULTS}

Pancytopenia was the most common indication for bone marrow aspiration. Out of 220 cases of bone marrow aspiration, megaloblastic anaemia was seen in 75 cases (34.1\%), dual deficiency anaemia in 47 cases $(21.4 \%)$ and erythroid hyperplasia in 23 cases (10.4\%). 15 cases (6.8\%) were diagnosed as acute leukaemia. There were 14 cases (6.4\%) of ITP, 8 cases (3.6\%) of ITP with megaloblastic anaemia, 12 cases (5.4\%) of hypoplastic marrow and 12 cases (5.4\%) of microcytic anaemia. Bone marrow was normal in 6 cases $(2.7 \%)$. Reactive plasmacytosis was seen in 4 cases $(1.8 \%)$ and one case of multiple myeloma was reported. Bone marrow metastasis and storage disorder involving marrow were seen in 2 cases $(0.9 \%)$ and 1 case $(0.45 \%)$ respectively.

\section{CONCLUSION}

Bone marrow examination plays a vital role in arriving at a confirmatory diagnosis in many of the benign and malignant haematological disorders. Nutritional anaemias, haematological malignancies and immune thrombocytopenias can be readily diagnosed by bone marrow aspiration alone, whereas hypoplastic anaemias require further workup.

\section{KEY WORDS}

Bone Marrow Aspiration, Benign Haematological Disorders, Megaloblastic Anaemia, Leukaemia, Non-Haematological Disorders. HOW TO CITE THIS ARTICLE: Kauser Z, Pathuri NK, Jeshtadi A, et al. Bone marrow examination- a two-year study at a tertiary care centre. J. Evolution Med. Dent. Sci. 2018;7(20):2442-2445, DOI: 10.14260/jemds/2018/549

\section{BACKGROUND}

The incidence of haematological diseases is quite alarming in Indian population. More so the benign acquired haematological conditions arising due to iron deficiency, B12 and folate deficiency etc. The commonest presenting symptom in most of these conditions is anaemia. Most often clinical examination and few simple investigations like complete blood counts and peripheral smear examination help us to diagnose the cause for anaemia. However, without bone marrow examination diagnosis is usually provisional. Bone marrow analysis plays a crucial role in diagnosis, confirmation of the diagnosis and in follow-up of treatment.

'Financial or Other Competing Interest': None.

Submission 23-04-2018, Peer Review 05-05-2018,

Acceptance 08-05-2018, Published 14-05-2018.

Corresponding Author:

Dr. Naga Kalyani Pathuri,

H. No. 16-3-989/c, Near Police Hospital,

Malakpet, Hyderabad-500024,

Telangana, India

E-mail: kalyani.pathuri@gmail.com

DOI: $10.14260 /$ jemds $/ 2018 / 549$
Many a times bone marrow examination forms the key to diagnose even a non-haematological condition also. Bone marrow aspiration is the most frequent and safe invasive procedure routinely done on an outpatient basis for diagnosis and management of haematological disorders. Bone marrow aspiration alone is sufficient to diagnose nutritional anaemias, most of acute leukaemias and immune thrombocytopenias. It is also particularly useful in unexplained cytopenias and sub-leukaemic leukaemias.

\section{Objective}

The present study was carried out to identify the frequency of various causes leading to bone marrow evaluation of a patient in our setup. The data was analysed and the bone marrow aspiration findings were interpreted.

\section{MATERIALS AND METHODS}

This is a retrospective descriptive study carried out at the Upgraded Department of Pathology, Osmania General Hospital, a tertiary care centre for a period of two years from July 2015 to June 2017. Bone marrow aspiration along with biopsies wherever required for suspected haematological 
disorders were carried out on 220 cases during the study period. Relevant clinical details, complete haemogram which includes blood cell counts, indices, peripheral smear findings, PCV and reticulocyte counts for all these cases were obtained from the records maintained in the Department of Pathology. Leishman stained bone marrow aspiration slides were retrieved and reviewed. Special stains were done on the bone marrow aspirate material wherever required.

\section{RESULTS}

Bone marrow examination of 220 cases of suspected haematological disorders was carried out.

\begin{tabular}{|c|c|c|}
\hline Indications & $\begin{array}{l}\text { No. of } \\
\text { Cases }\end{array}$ & Percentage \\
\hline Pancytopenia & 72 & $32.7 \%$ \\
\hline Bicytopenia & 58 & $26.4 \%$ \\
\hline Anaemia & 42 & $19.1 \%$ \\
\hline Petechiae & 14 & $6.4 \%$ \\
\hline $\begin{array}{l}\text { Pyrexia of unknown } \\
\text { origin }\end{array}$ & 15 & $6.8 \%$ \\
\hline Organomegaly & 5 & $2.3 \%$ \\
\hline Others & 14 & $6.4 \%$ \\
\hline \multicolumn{3}{|c|}{ Table 1. Indications for Bone Marrow Aspiration } \\
\hline
\end{tabular}

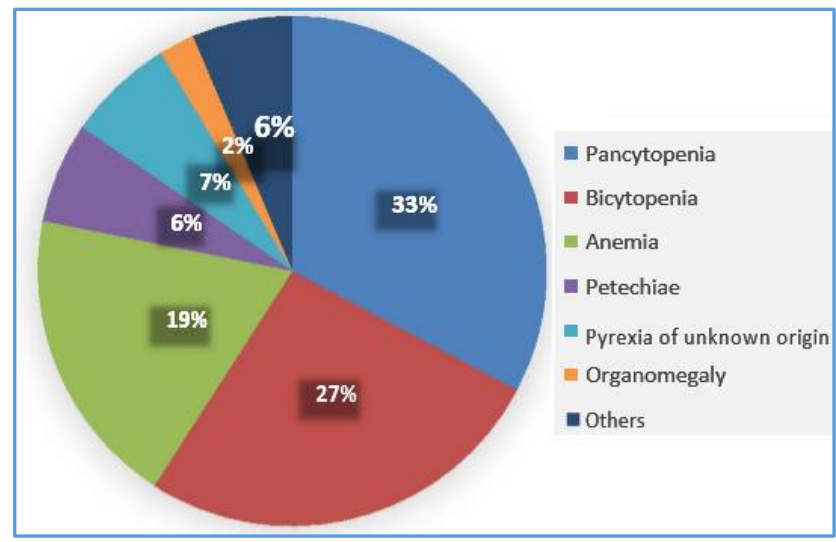

Chart 1

Commonest indication for bone marrow aspiration was pancytopenia followed by bicytopenia and anaemia. Other indications were petechiae, pyrexia of unknown origin, hepatomegaly, splenomegaly, gum bleeding and lymphadenopathy.

\begin{tabular}{|c|c|c|}
\hline Age Group & $\begin{array}{c}\text { No. of } \\
\text { Patients }\end{array}$ & Percentage \\
\hline$<15$ years & 17 & $7.7 \%$ \\
\hline $15-29$ years & 67 & $30.5 \%$ \\
\hline $30-45$ years & 91 & $41.3 \%$ \\
\hline$>45$ years & 45 & $20.5 \%$ \\
\hline Total & $\mathbf{2 2 0}$ & $\mathbf{1 0 0} \%$ \\
\hline \multicolumn{2}{|c|}{ Table 2. Age Distribution of Patients } \\
\hline
\end{tabular}

Age of the patients in our study ranged from 5 years to 72 years. Most common age group undergoing bone marrow aspiration was 30 - 45 years, whereas mean age was 34 years. 128 (58.2\%) were males and 92 (41.8\%) were females with (M: $\mathrm{F}=1.4: 1)$.

\begin{tabular}{|c|c|c|}
\hline BMA Diagnosis & No. of Cases & Percentage \\
\hline Megaloblastic anaemia & 75 & $34.1 \%$ \\
\hline Dual deficiency anaemia & 47 & $21.4 \%$ \\
\hline $\begin{array}{l}\text { Erythroid hyperplasia in } \\
\text { response to treatment }\end{array}$ & 23 & $10.4 \%$ \\
\hline Acute Leukaemia & 15 & $6.8 \%$ \\
\hline ITP & 14 & $6.4 \%$ \\
\hline $\begin{array}{l}\text { ITP with Megaloblastic } \\
\text { anaemia }\end{array}$ & 8 & $3.6 \%$ \\
\hline Hypoplastic marrow & 12 & $5.4 \%$ \\
\hline Iron deficiency anaemia & 12 & $5.4 \%$ \\
\hline Normal marrow & 6 & $2.7 \%$ \\
\hline Reactive plasmacytosis & 4 & $1.8 \%$ \\
\hline Plasma cell dyscrasias & 1 & $0.45 \%$ \\
\hline Bone marrow metastasis & 2 & $0.9 \%$ \\
\hline Storage disorder & 1 & $0.45 \%$ \\
\hline
\end{tabular}

\begin{tabular}{|c|c|c|}
\hline BMA Diagnosis & $\begin{array}{c}\text { No. of } \\
\text { Cases }\end{array}$ & Percentage \\
\hline Megaloblastic anaemia & 40 & $55.5 \%$ \\
\hline Dual deficiency anaemia & 18 & $25 \%$ \\
\hline Hypoplastic marrow & 12 & $16.6 \%$ \\
\hline Sub-Leukaemic Leukaemia & 01 & $1.4 \%$ \\
\hline Plasma cell dyscrasias & 01 & $1.4 \%$ \\
\hline \multicolumn{2}{|c|}{ Table 4. BMA Findings in Cases of Pancytopenia } \\
\hline
\end{tabular}

Out of 220 cases of bone marrow aspiration megaloblastic anaemia was seen in 75 cases (34.1\%), dual deficiency anaemia in 47 cases (21.4\%) and erythroid hyperplasia in 23 cases (10.4\%). 15 cases (6.8\%) were diagnosed as acute leukaemia. There were 14 cases $(6.4 \%)$ of ITP, 8 cases $(3.6 \%)$ of ITP with megaloblastic anaemia, 12 cases (5.4\%) of hypoplastic marrow and 12 cases (5.4\%) of microcytic anaemia. Bone marrow was normal in 6 cases (2.7\%). Reactive plasmacytosis was seen in 4 cases $(1.8 \%)$ and one case of multiple myeloma was reported. Bone marrow metastasis and storage disorder involving marrow were seen in 2 cases $(0.9 \%)$ and 1 case $(0.45 \%)$ respectively.

Megaloblastic anaemia was the most common finding seen in 75 cases (34.1\%) in our study. Most of them presented as pancytopenia followed by bicytopenia and anaemia. All cases diagnosed as megaloblastic anaemia correlated with low serum B12 and red cell folate levels. Dual deficiency anaemia was seen in 47 cases (21.4\%).

Erythroid hyperplasia in response to treatment for megaloblastic anaemia was seen in 23 cases (10.4\%). These cases showed no other significant findings on bone marrow. Acute leukaemia was seen in 15 cases (6.8\%). Of these, 9 cases were AML and 6 cases (1.8\%) were ALL.

Only ITP was seen in 14 cases. ITP with megaloblastic anaemia was seen in 8 cases. Interestingly, all cases of hypoplastic marrow 12 cases (5.4\%) had history of herbal medicine intake. Iron deficiency anaemia was an uncommon finding in our study, seen only in 12 cases (5.4\%). Bone marrow aspiration was done in iron deficiency anaemia for iron stores. Normal marrow was seen in 6 cases $(2.7 \%)$. Reactive plasmacytosis was seen in 4 cases $(1.8 \%)$. One case of multiple myeloma was reported. Patient was 50 years old male, presented with wedge compression of lumbar spine and nephrotic range proteinuria. He also had associated light chain deposition disease in kidney.

Two cases of metastatic deposits were reported. One was a case of Signet ring cell adenocarcinoma, which presented 
with normocytic normochromic anaemia. This was a case of 70 years old male. Bone marrow aspirate showed clusters of atypical cells, few arranged in glandular pattern. Endoscopic biopsy of the patient showed Signet ring cells. The other case had leukoerythroblastic picture and anaemia. This was a case of a 58-year-old female who was recently diagnosed case of carcinoma breast with multiple bone and marrow metastasis.

One case of Gaucher's disease was reported. It was a case of 43-year-old male who presented with massive splenomegaly and microcytic hypochromic anaemia. Marrow aspirate showed plump macrophages that characteristically have the appearance in the cytoplasm of crumpled tissue paper.

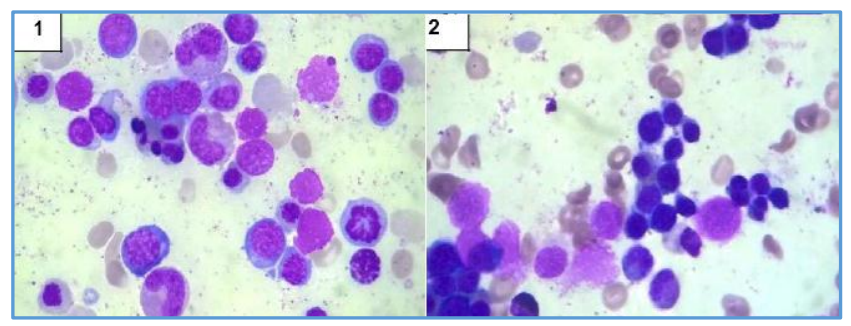

Figure 1. Photomicrograph of Megaloblastic Anaemia; aspirate shows Megaloblasts with Sieve-Like Chromatin and Giant Metamyelocyte (Leishman Stain 1000x).

Figure 2. Photomicrograph of Iron Deficiency Anaemia: Marrow Aspirate showing Erythroblasts with Scant Cytoplasm and Ragged Cytoplasmic Borders with Eccentric Nuclei and Basophilic Cytoplasm with Perinuclear Hoff (Leishman Stain 1000x).

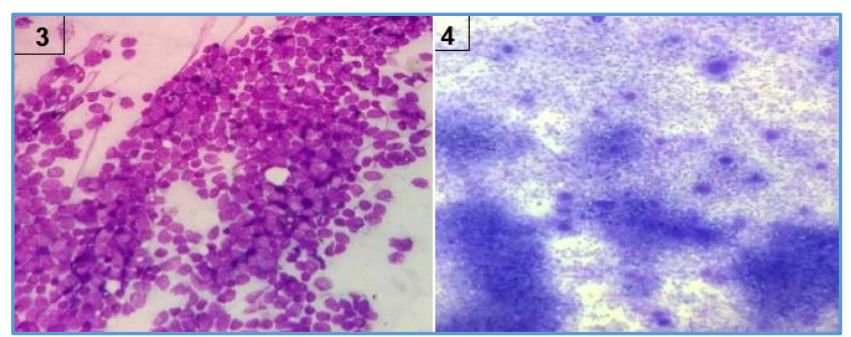

Figure 3. Photomicrograph of Acute Lymphoblastic Lymphoma: Marrow Aspirate shows Hypercellular Marrow replaced by Lymphoblasts (Leishman Stain 400x).

Figure 4. Photomicrograph of Immune

Thrombocytopenic Purpura: Marrow Aspirate showing Increased Megakaryocytes (Leishman Stain 100x).

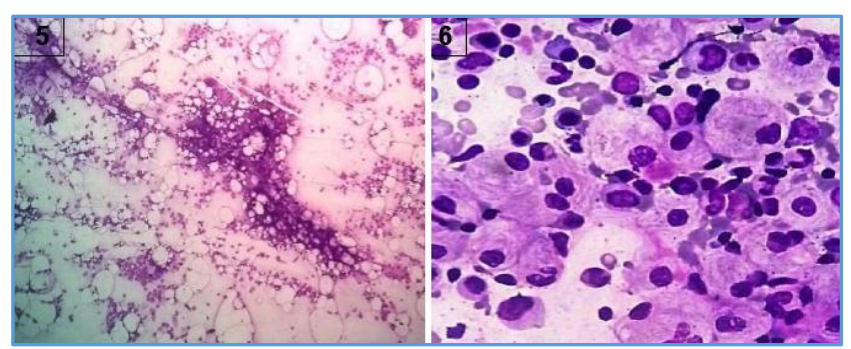

Figure 5. Photomicrograph of Hypoplastic Marrow Aspirate showing Hypocellularity with Increased Fat Spaces in a 20 years old male (Leishman Stain $\times 100$ ). Figure 6. Photomicrograph of Gaucher Disease involving Marrow: Marrow Aspirate showing Plump Macrophages that characteristically have the appearance in the Cytoplasm of Crumpled Tissue Paper (Leishman Stain 1000x).

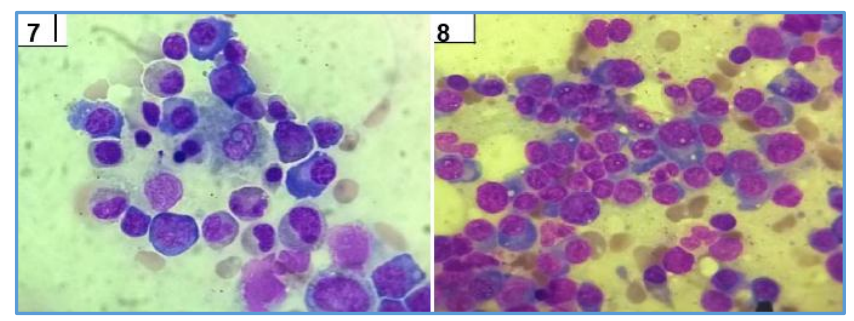

Figure 7. Photomicrograph of Reactive Plasmacytosis Marrow Aspirate showing Mature Plasma Cells with Eccentric Nuclei and Basophilic Cytoplasm with Perinuclear Hoff (Leishman Stain 1000x).

Figure 8. Photomicrograph of Multiple Myeloma: Marrow Aspirate showing Mature and Immature Plasma Cells with Dutcher Bodies and Plasma Blasts (Leishman Stain 1000x).

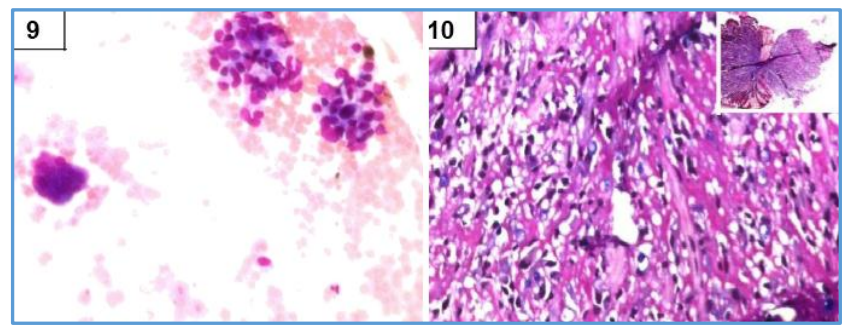

Figure 9. Photomicrograph of Bone Marrow Aspirate showing Clusters of Pleomorphic Cells, few arranged in Glandular Pattern (Leishman Stain 400x).

Figure 10. Alcian Blue Stained Endoscopic Biopsy showing Signet Ring Cells.

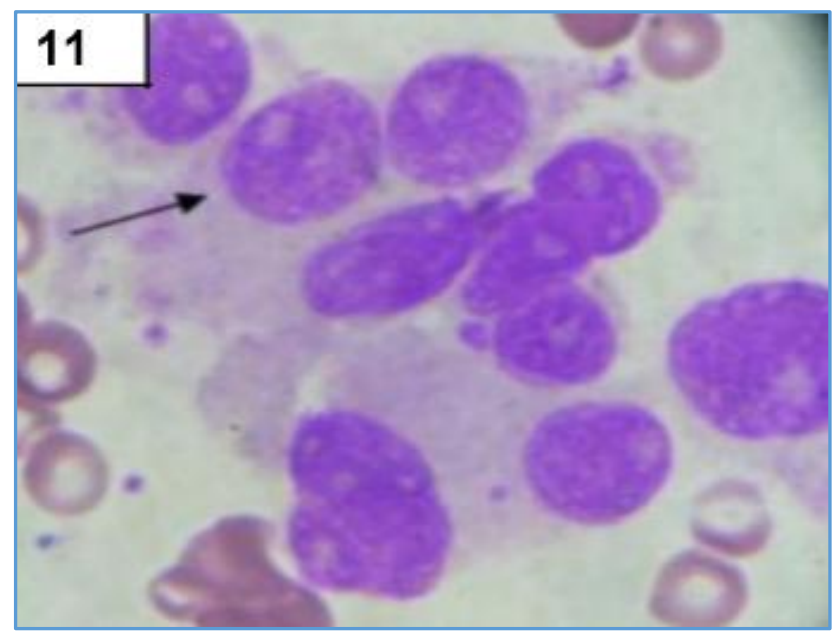

Figure 11. Photomicrograph of Bone Marrow Aspirate showing Cluster of Large Pleomorphic Round-to-Oval Cells with Scant Cytoplasm, Coarse Chromatin and 1 or 2 prominent Nucleoli (Leishman Stain 1000x).

\section{DISCUSSION}

Spectrum of haematological disorders is very wide. Bone marrow examination is safe and a useful test in reaching the final diagnosis after preliminary investigations. ${ }^{1}$ Pancytopenia was the most common indication for bone marrow aspiration in our study similar to study done by Ahmed et al. ${ }^{2}$ But in contrast to these studies, pancytopenia was the third common indication (11.9\%) in a study done by Bashawri et al. ${ }^{3}$ In concordance with studies by Vermanidhi et al and Sachin D Tonape et al, our study also showed megaloblastic anaemia as most common cause of pancytopenia. 


\begin{tabular}{|c|c|c|c|c|}
\hline$\overbrace{\tilde{n}}^{\vec{Z}}$ & 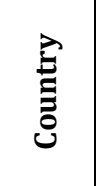 & 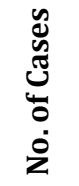 & 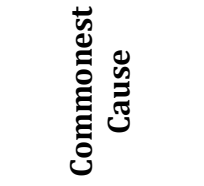 & 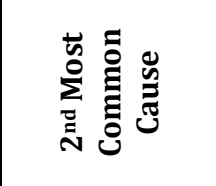 \\
\hline $\begin{array}{l}\text { Khodke et al } \\
(2000)^{4}\end{array}$ & India & 166 & $\begin{array}{c}\text { Hypoplastic } \\
\text { Anaemia } \\
(29.5 \%)\end{array}$ & $\begin{array}{c}\text { Megaloblastic } \\
\text { Anaemia } \\
(22.3 \%) \\
\end{array}$ \\
\hline $\begin{array}{l}\text { Verma Nidhi } \\
\text { et al }(2012)^{5}\end{array}$ & India & 72 & $\begin{array}{c}\text { Megaloblastic } \\
\text { Anaemia } \\
(40.3 \%)\end{array}$ & $\begin{array}{c}\text { Aplastic } \\
\text { Anaemia } \\
(22.2 \%)\end{array}$ \\
\hline $\begin{array}{c}\text { Sachin D } \\
\text { Tonape et al } \\
(2013)^{6} \\
\end{array}$ & India & 210 & $\begin{array}{c}\text { Megaloblastic } \\
\text { Anaemia } \\
(65.7 \%) \\
\end{array}$ & $\begin{array}{c}\text { Aplastic } \\
\text { Anaemia }(16 \%)\end{array}$ \\
\hline $\begin{array}{c}\text { Present Study } \\
\text { (2015) }\end{array}$ & India & 72 & $\begin{array}{c}\text { Megaloblastic } \\
\text { Anaemia } \\
(55.5 \%)\end{array}$ & $\begin{array}{l}\text { Dual Deficiency } \\
\text { Anaemia }(25 \%)\end{array}$ \\
\hline 7 & W & & Commonest & use \\
\hline
\end{tabular}

In our study, Megaloblastic anaemia was the commonest cause of pancytopenia and also most common diagnosis on bone marrow aspiration like in study by Gayathri et al. ${ }^{7}$ All cases of megaloblastic anaemia had either low serum folic acid or vitamin B12 levels or both. This group of patients responded very well to the appropriate therapy. Whereas in studies done by Niazi et al and Jha et al megaloblastic anaemia was the second most common diagnosis.8,9 This increased incidence of megaloblastic anaemia correlates with the high prevalence of nutritional anaemias in our country. ${ }^{10}$

Hypoplastic marrow was seen in 12 cases (5.4\%). Diagnosis of hypoplastic marrow was based on BMA findings alone. All patients with hypoplastic marrow had history of herbal medicine intake. Ideally in all the cases of peripheral pancytopenia, especially if hypoplastic or aplastic anaemia is suspected, both aspiration and trephine biopsy should be done simultaneously because bone marrow biopsy gives a more reliable index of cellularity and reveals bone marrow infiltration, fibrosis and granulomas. Compared to our study $19 \%, 29 \%$ and $14 \%$ cases of hypoplastic anaemia were seen in other studies. $4,7,9$

Both ITP and pernicious anaemia have autoimmune basis. Association of these disorders is well known. Our study also had 8 cases (3.6\%) of ITP with megaloblastic anaemia.

Erythroid hyperplasia was seen in 23 cases (10.4\%). All cases with erythroid hyperplasia were on treatment for megaloblastic anaemia and this marrow showed no other significant findings. In a study by Pudasaini $\mathrm{S}$ et al, erythroid hyperplasia was the most common finding. ${ }^{10}$

There are many causes of reactive bone marrow plasmacytosis including infection, malignancy, inflammation, Castleman's disease, iron deficiency, megaloblastic anaemia, haemolytic anaemia, diabetes mellitus, cirrhosis and streptokinase treatment.

Metastatic tumours in bone marrow may influence the tumour stage, response to treatment and predicts the survival of patient. Hence, it is important to diagnose such cases at the earliest. Infiltration of the bone marrow should be suspected in cases with unexplained cytopenias or a leukoerythroblastic picture on routine blood and peripheral smear examination. Gastric neoplasm may rarely involve the marrow, therefore should be considered in the differential diagnosis of metastatic bone lesions with unknown primary. Bone is the most common site for distant metastases in breast cancer. Breast cancer metastasis may camouflage multiple myeloma by lytic lesions. Strong clinical suspicion and thorough haematological workup is necessary for diagnosis.

\section{CONCLUSION}

Bone marrow examination is important to arrive at the confirmatory diagnosis of many haematological disorders. Nutritional anaemias, haematological malignancies and immune thrombocytopenia can be readily diagnosed by bone marrow aspiration alone, whereas hypoplastic anaemias require further workup. Increased incidence of megaloblastic anaemia correlates with the high prevalence of nutritional anaemias in our country. Infiltration of the bone marrow should be suspected in cases of unexplained cytopenias or a leukoerythroblastic picture on routine blood and peripheral smear examination.

\section{REFERENCES}

[1] Kibria SG, Islam MDU, Chowdhury ASMJ, et al. Prevalence of hematological disorder: a bone marrow study of 177 cases in a private hospital at Faridpur. Faridpur Med Coll J 2010;5(1):11-3.

[2] Ahmad SQ, Khan OU, Zafar N. Utility of bone marrow examination in a secondary care hospital. JRMC 2011;15:40-1.

[3] Bashawri LA. Bone marrow examination. Indications and diagnostic value. Saudi Med J 2002;23(2):191-6.

[4] Khodke K, Marwah S, Buxi G, et al. Bone marrow examination in cases of pancytopenia. J Acad Clin Med 2001;2:55-9.

[5] Verma N, Malik H, Sharma VK, et al. Etiology of pancytopenia in and around meerut. JARMS 2012;4(2):145-51.

[6] Tonape SD, Shende NT. To study hemogram and bone marrow morphology (Aspiration/Biopsy) in cases of pancytopenia at GMC \& $\mathrm{H}$ Nagpur-two year observational study. Translational Medicine and Biotechnology ISSN 2350-1073, 2014.

[7] Gayathri BN, Rao KS. Pancytopenia: a clinico hematological study. J Lab Physicians 2011;3(1):1520.

[8] Niazi M, Raziq FI. The incidence of underlying pathology in pancytopenia-an experience of 89 cases. JPMI 2004;18(1):76-9.

[9] Jha A, Sayami G, Adhikari RC, et al. Bone marrow examination in cases of pancytopenia. J Nepal Med Assoc 2008;47(169):12-7.

[10] Pudasaini S, Prasad KBR, Rauniyar SK, et al. Interpretation of bone marrow aspiration in hematological disorder. J Pathol Nepal 2012;2:309-12. 